\title{
Metodologias colaborativas não extrativistas e comunicação: articulando criativamente saberes e sentidos para a emancipação social
}

\author{
Non-extractive collaborative methodologies and communication: \\ combining knowledge and feelings in a creative way for social emancipation
}

\section{Metodologías colaborativas no extractivistas y comunicación: uniendo saberes y sentidos con creatividad para la emancipación social}

Marina Tarnowski Fasanello ${ }^{1, a}$

mtfasanello@gmail.com | https://orcid.org/o00o-0003-4759-5075

João Arriscado Nunes ${ }^{2, b}$

jan@ces.uc.pt | https://orcid.org/o000-0003-0109-8268

Marcelo Firpo de Souza Porto ${ }^{3, c}$

mfirpo2@gmail.com | https://orcid.org/0000-0002-9007-0584

\footnotetext{
${ }^{1}$ Fundação Oswaldo Cruz, Escola Nacional de Saúde Pública Sérgio Arouca, Núcleo Ecologias, Epistemologias e Promoção Emancipatória da Saúde. Rio de Janeiro, RJ, Brasil.

${ }^{2}$ Universidade de Coimbra, Centro de Estudos Sociais. Coimbra, Portugal.

${ }^{3}$ Fundação Oswaldo Cruz, Escola Nacional de Saúde Pública Sérgio Arouca, Centro de Estudos em Saúde do Trabalhador e Ecologia Humana. Rio de Janeiro, RJ, Brasil.

a Doutorado em Ciências pela Fundação Oswaldo Cruz.

${ }^{b}$ Doutorado em Sociologia pela Universidade de Coimbra.

c Doutorado em Engenharia de Produção pela Universidade Federal do Rio de Janeiro.
}

\section{Resumo}

Este artigo discute a proposição de metodologias colaborativas não extrativistas e sua relação com a comunicação a partir da obra de Boaventura de Sousa Santos. Partindo de autores como Orlando Fals Borda e Paulo Freire, Santos questiona as metodologias qualitativas que extraem conhecimentos apartados das lutas sociais e não reconhecem os saberes dos sujeitos investigados. A partir desse referencial e de uma pesquisa sobre documentários produzidos no contexto das lutas sociais contra os agrotóxicos e pela agroecologia, buscamos levantar possibilidades metodológicas relacionais que apontem para processos de co-labor-ação e co-criação. A construção de novas narrativas e conhecimentos dilui fronteiras entre ciência e arte, ao mesmo tempo que resgata e avança na perspectiva freiriana da comunicação enquanto um tornar comum. Entrevistas narrativas e contação de histórias da literatura oral são exemplos dados no artigo que apontam para uma abordagem teórico-poética como alternativa.

Palavras-chave: Comunicação; Metodologia qualitativa colaborativa; Epistemologias do Sul; Entrevista narrativa; Arte. 


\begin{abstract}
This article discusses the proposal of non-extractive collaborative methodologies and their relationship to the communication based on the works of Boaventura de Sousa Santos. Based on authors such as Orlando Fals Borda and Paulo Freire, Santos questions qualitative methodologies which extract knowledge that is separated from social struggles, and also they not recognize the knowledge of the investigated subjects. Based on this reference and a research on documentaries produced in the context of social struggles against pesticides and agroecology, we seek to raise methodological relational possibilities that point to processes of co-labor-action and co-creation. The construction of new narratives and knowledge dilutes the rigid boundaries between science and art; moreover, it restores and advances in the Freirean perspective to become the communication a common action. Narrative interviews and storytelling of oral literature are examples given in this article that point to a theoretical poetic approach as an alternative to qualitative methodology.
\end{abstract}

Keywords: Communication; Qualitative methodology; South epistemology; Narrative interviews; Art.

\title{
Resumen
}

Este artículo discute la proposición de metodologías colaborativas no extractivistas y su relación con la comunicación a partir de la obra de Boaventura de Sousa Santos. Basado en autores como Orlando Fals Borda y Paulo Freire, Santos cuestiona las metodologías cualitativas que extraen conocimientos apartados de las luchas sociales, al mismo tiempo que no reconocen los saberes de los sujetos investigados. A partir de ese referencial y de una investigación sobre documentales producidos en el contexto de las luchas sociales contra los agrotóxicos y la agroecología, buscamos levantar posibilidades metodológicas relacionales que apunten a procesos de co-labor-acción y co-creación. La construcción de nuevas narrativas y conocimientos diluye fronteras entre ciencia y arte, al mismo tiempo que recobra y avanza en la perspectiva freireana de la comunicación mientras un hacer común. Entrevistas narrativas y narraciones de cuentos de la literatura oral son ejemplos dados en el artículo que apuntan para un enfoque teórico poético como alternativa.

Palabras clave: Comunicación; Metodología cualitativa; Epistemología del sur; entrevistas narrativas; Arte.

\section{Contribuição dos autores:}

Concepção e desenho do estudo: Como o artigo reflete uma abordagem qualitativa baseada em desenvolvimento teórico para realização de tese de doutorado da primeira autora, esta teve um papel relevante na concepção, desenho e escrita, com o suporte dos outros dois coautores, que também atuaram como co-orientadores.

Aquisição, análise ou interpretação dos dados: Idem.

Redação do manuscrito: Idem.

Revisão crítica do conteúdo intelectual: Idem.

Declaração de conflito de interesses: Não há.

Fontes de financiamento: CNPq - Conselho Nacional de Desenvolvimento Científico e Tecnológico e Faperj - Fundação Carlos Chagas de Apoio à Pesquisa do Estado do Rio de Janeiro.

Considerações éticas: $\mathrm{O}$ artigo foi baseado em tese de doutorado cujo projeto foi aprovado pelo Comitê de Ética em Pesquisa do Instituto de Comunicação e Informação Científica e Tecnológica em Saúde da Fundação Oswaldo Cruz.

Agradecimentos/Contribuições adicionais: Não há.

Histórico do artigo: Submetido: 19.abr.2018 | Aceito: 18.ago.2018 | Publicado: 21dez.2018.

Apresentação anterior: Não houve.

Licença CC BY-NC atribuição não comercial. Com essa licença é permitido acessar, baixar (download), copiar, imprimir, compartilhar, reutilizar e distribuir os artigos, desde que para uso não comercial e com a citação da fonte, conferindo os devidos créditos de autoria e menção à Reciis. Nesses casos, nenhuma permissão é necessária por parte dos autores ou dos editores. 


\section{Introdução}

Este artigo discute o desenvolvimento de pesquisas qualitativas tendo por referência a noção de metodologias colaborativas não extrativistas e sua relação com a comunicação, entendida não apenas como um campo de conhecimentos e práticas, mas também como um componente irredutível dos possíveis encontros e diálogos entre pessoas e grupos sociais com seus saberes, culturas e lutas por dignidade. A noção de metodologias colaborativas vem sendo desenvolvida por Boaventura de Sousa Santos e seu grupo de pesquisa noâmbito das chamadas epistemologias do Sul, em estreita relação com conceitos comolinha abissal, pensamento pós-abissal, ecologia dos saberes, tradução intercultural e artesania das práticas. A discussão metodológica realizada recentemente por Santos $^{1}$ articula-se fortemente com dimensões educacionais e pedagógicas da transformação social trabalhadas, anteriormente, de forma seminal pelos autores latinoamericanos Paulo Freire e Orlando Fals Borda. Em nosso artigo, incorporamos a dimensão da comunicação também trabalhadas por esses autores, que consideram a comunicação um processo relacional, um ato de reciprocidade e um tornar comum dialógico em que não há sujeitos passivos em contextos de dominação e lutas por existência em sociedades capitalistas, e as epistemologias do Sul ampliam o escopo da dominação para as dimensões coloniais e patriarcais. Freire e Fals Borda são estratégicos porque dedicaram sua obra ao enfrentamento das tensões e alternativas entre ciência e saberes populares, conhecimento e razão, teoria e prática, transformação social e status quo, entre sujeito e objeto ou objetividade e subjetividade ${ }^{2,3}$.

Nos embasamos no material empírico de uma pesquisa de doutorado sobre a produção de documentários que articulam cineastas, movimentos sociais do campo, instituições e pesquisadores no campo da saúde coletiva em torno de dar visibilidade às suas três lutas: (i) o uso de agrotóxicos enquanto um problema ambiental e de saúde pública; (ii) o agronegócio enquanto expressão da agricultura capitalista globalizada voltada à produção de commodities rurais para o comércio internacional baseado em monocultivos químico-dependentes, na concentração fundiária e de capital; (iii) a defesa da reforma agrária e da produção agrícola familiar, camponesa e agroecológica como alternativa de transformação social que responde aos desafios anteriores.

Inserida no Programa de Pós-Graduação em Informação e Comunicação em Saúde, do Icict/Fiocruz, a pesquisa assume que as lutas sociais emancipatórias de nosso tempo envolvem disputas por visibilidade, ou seja, por melhores condições de produzir e fazer circular os sentidos e demandas dos movimentos sociais frente a formas hegemônicas, opressoras e invisibilizadoras de realidades e alternativas ${ }^{4}$. Buscamos aprofundar a compreensão da dimensão transformadora do discurso, estabelecendo conexões entre o modo de produção, circulação e apropriação dos sentidos e a natureza da prática social, na sua relação com as estruturas e as lutas sociais 5 . A partir de tais referenciais, a comunicação é analisada na pesquisa como um ciclo, um processo de produção, circulação e apropriação constituído por múltiplos e diversos interlocutores com desiguais poderes não só para produzir, mas também para fazer circular seus modos de ver as coisas da vida e do mundo ${ }^{6}$.

Compreender a comunicação em sua relação com o enfrentamento das desigualdades significa também perceber e reverter o silenciamento sistemático dos discursos que objetivam desconstruir pensamentos e práticas hegemônicos que excluem, de diferentes formas, sujeitos e seus saberes, assim como outros projetos de sociedade. Em outras palavras, trata-se de melhor compreender a dimensão comunicacional no âmbito dos movimentos sociais articulados em redes e alianças com diferentes organizações, instituições e pesquisadores relacionados às estratégias das lutas de tais movimentos por reconhecimento e dignidade 5 . A proposta deste artigo é também avançar metodologicamente a partir do paradigma freiriano que fundamenta as epistemologias do Sul, fornecendo elementos que permitam futuramente melhor articular a ideia da comunicação enquanto o tornar comum, com as bases teóricas da comunicação que a assume como um mercado simbólico de disputas e assimetrias em uma sociedade desigual. Para as epistemologias do Sul, a compreensão das estratégias comunicativas implica a construção de métodos colaborativos que permitam 
avançar nas lutas e resistências voltadas ao fortalecimento e à autonomia das vozes subalternizadas, em nosso caso de camponeses e movimentos sociais do campo em luta contra o modelo perverso de desenvolvimento agrário imposto pela agricultura industrial capitalista. Há, portanto, mais que disputas de poder e pontos de vista em jogo, já que a perspectiva freiriana e das epistemologias do Sul assume um lado ético e político para além da superação das desigualdades: a dimensão ética e política é simultaneamente ontológica, epistemológica e comunicacional. Portanto, possui lado claros nas lutas sociais em jogo, que são simultaneamente anticapitalistas, anticoloniais e antipatriarcais.

Ao longo da pesquisa buscou-se, mais que compreender tais lutas e suas estratégias, pensar em objetos de pesquisa e metodologias de investigação que avancem na possibilidade de apoiar tais lutas e transformações sociais a partir de diferentes narrativas que emerjam simultaneamente enquanto uma pluralidade de vozes, experiências e saberes. Nesse sentido, houve uma crescente aproximação com o referencial das epistemologias do Sul, o que gerou reflexões com desdobramentos metodológicos acerca das condições de realização de entrevistas e dos processos de construção de relatos significativos, expressão esta que será trabalhada mais à frente. Tal aproximação resultou em uma articulação teórica entre as dimensões comunicacionais e epistemológicas ${ }^{7}$ e, posteriormente, desembocou na ideia de metodologias colaborativas não extrativistas como alternativa para pensar um trilhar metodológico que, a par de permitir a consecução dos objetivos previstos para a pesquisa, guarde coerência com a fundamentação das epistemologias do Sul. Contudo, neste artigo não temos a pretensão de aprofundar as tensões e possibilidades de articulação entre diferentes paradigmas, uma vez que isso envolveria tensões e possibilidades de superação que ultrapassam os limites propostos para ele. Por exemplo, ao nos posicionarmos claramente ao lado dos excluídos radicalmente, pode levar à perda da objetividade e a criação de análises maniqueístas quanto às disputas em jogo. Certamente, esse é um dos grandes desafios permanentemente enfrentado pelas epistemologias do Sul.

A pesquisa referida está inserida em uma cooperação acadêmica mais ampla entre a Fundação Oswaldo Cruz e o Centro de Estudos Sociais (CES) da Universidade de Coimbra, fundado em 1978 e dirigido por Boaventura de Sousa Santos. O CES é o principal palco acadêmico da construção, no âmbito das teorias pós-coloniais, do que veio a ser denominado por Boaventura de Sousa Santos e seu grupo de pesquisa como as epistemologias do Sul.

Ao longo do artigo, buscamos refletir sobre a construção de metodologias colaborativas não extrativistas sob a lente das epistemologias do Sul a partir de um conjunto de questões que o orientam e o organizam. Na próxima seção, apresentamos o significado/definição das epistemologias do Sul e a recente proposição de metodologias colaborativas não extrativistas. Em seguida, discutimos a relação entre as epistemologias do Sul e a comunicação, compreendida como o ‘tornar comum' a partir de processos dialógicos, em particular no contexto das lutas travadas por populações excluídas e movimentos sociais. Ou seja, como podemos compreender a comunicação frente às estratégias de dominação e resistência que caracterizam a crise civilizatória e como perceber o papel da comunicação na criação de alternativas emancipatórias.

Na seção seguinte, damos continuidade ao tema das metodologias colaborativas não extrativistas, abordando alguns dos limites das metodologias qualitativas convencionais, e sugerimos alguns princípios e estratégias de avanços com o apoio de noções como co-criaçãoi, performance e artesania das práticas. Inspiramo-nos em Boaventura de Sousa Santos e em autores que discutem o papel da arte, das narrativas e das histórias da literatura oral ${ }^{8,9}$ na construção de novas abordagens metodológicas e pedagógicas a serem consideradas na investigação e produção de conhecimentos. Para tais autores, a racionalidade lógica e logocêntrica, expressa exclusivamente pela linguagem falada e escrita, não pode captar diferentes enunciações, sentidos e saberes fundamentais aos processos relacionais e dialógicos. Estes necessitam de

i A intenção do uso de hífen nessas e outras palavras expressam a ideia da articulação conjunta para além das ações isoladas ou individuais. 
formas sensíveis de expressão para que sejam percebidos e possam gerar outras formas de comunicação. Só assim serão coerentes e efetivos. Essa discussão é complementada por outra, que apresenta a proposta de entrevista narrativa e do uso de histórias da literatura oral para a sensibilização e construção de intersubjetividades que possibilitem a emergência de relatos significativos, e foi assumida como contribuição da pesquisa já mencionada. Por fim, concluímos o artigo sugerindo uma abordagem teórico-poética ${ }^{9}$ como um dos componentes das metodologias colaborativas que, ao incorporar diferentes linguagens e formas de expressão no processo dialógico a partir de narrativas, pode contribuir para o desenvolvimento de novas metodologias colaborativas a partir do resgate não apenas dos elos silenciados (noção que será trabalhada mais à frente) associados às violências abissais, mas de conhecimentos e projetos utópicos que envolvam e integrem amplamente sentidos, saberes e sonhos emancipatórios construídos nas frestas das opressões e distopias em curso.

\section{Epistemologias do sul e metodologias colaborativas não extrativistas}

As epistemologias do Sul podem ser compreendidas como um amplo corpo teórico crítico e em construção que propõe um pensamento alternativo para enfrentar o pensamento único da modernidade eurocêntrica. No prefácio do livro que tem como título Epistemologias do $\mathrm{Sul}^{10}$, encontramos as perguntaschave cujas respostas orientam sua criação: “[...] Por que razão, nos dois últimos séculos, dominou uma epistemologia que eliminou da reflexão epistemológica o contexto cultural e político da produção e reprodução do conhecimento? Quais foram as consequências de uma tal descontextualização? São hoje possíveis outras epistemologias?”.

No mesmo prefácio esclarece-se que as epistemologias do Sul buscam responder tais questões e são definidas como um “[...] conjunto de intervenções epistemológicas que denunciam a supressão dos saberes levada a cabo, ao longo dos últimos séculos, pela norma epistemológica dominante, valorizam os saberes que resistiram com êxito e as reflexões que estes têm produzido e investigam as condições de um diálogo horizontal entre conhecimentos. A esse diálogo entre saberes chamamos ecologias de saberes"10.

Um dos conceitos mais importantes e originais das epistemologias do Sul é o pensamento abissal, ou ainda a linha abissal ${ }^{11}$. Eles fazem parte de uma proposta epistemológica e política para entender como a modernidade, em sua tríplice forma de dominação (capitalismo, colonialismo e patriarcado), mais que excluir trabalhadores explorados, exclui radicalmente pessoas da condição de humanos e sujeitos portadores de direitos e saberes. A linha abissal é simultaneamente radical, invisível e invisibilizadora, e se encontra por detrás de fenômenos como o racismo, a xenofobia e outras formas de violência contra indígenas, favelados, mulheres e homossexuais, entre outros grupos presentes no 'Sul Global '. Este inclui os países das regiões periféricas e semiperiféricas do sistema-mundo moderno, também denominadas 'Terceiro Mundo`após a II Guerra Mundial ${ }^{10}$. Trata-se, porém, de um conceito dinâmico que transcende divisões geográficas, já que podemos falar de um Norte dentro do Sul, e de um Sul dentro do Norte.

O conceito de linha abissal rompe com a ideia de que os objetivos de inclusão social estão abertos a todos, seja pela utopia socialista ou pela liberal. Além da luta contra a exclusão social e econômica do capitalismo, há outra luta com implicações simultaneamente políticas e epistemológicas. A linha abissal poder ser entendida como a que “[...] impede a co-presença do universo “deste lado da linha” com o universo “do outro lado da linha”. Do lado de lá, não estão os excluídos, mas os seres sub-humanos não candidatos à inclusão social. A negação dessa humanidade é essencial à constituição da modernidade, uma vez que é condição para que o lado de cá possa afirmar a sua universalidade. Assim, práticas que não se encaixam nas teorias não põem em causa essas teorias, e práticas desumanas não põem em causa os princípios da humanidade"12 .

Um grande desafio assumido pelas epistemologias do Sul é construir um pensamento pós-abissal, uma síntese da ideia de transição utópica para uma sociedade pós-capitalista, pós-colonial e pós-patriarcal. Segundo Santos ${ }^{11}$, um pensamento pós-abissal exige uma sociologia pós-abissal baseada em pelo menos dois princípios: o primeiro é construir conhecimentos a partir da perspectiva dos que sofrem as exclusões 
radicais, e não exclusivamente a partir de uma ciência que se arroga detentora da única fonte de saber legítimo e confiável. Daí a importância de a ciência e os cientistas reconhecerem seus limites e saberem dialogar com outros saberes externos à própria ciência e presentes nas visões de mundo, práticas e lutas dos excluídos do 'Sul Global ’

O segundo princípio, de especial relevância para este artigo, é conhecer 'com' e não 'sobre', base da ideia de uma metodologia colaborativa não extrativista, que vem sendo desenvolvida recentemente por Boaventura de Sousa Santos ${ }^{1}$ em sua busca de avançar a partir de trabalhos de intelectuais como Paulo Freire e Orlando Fals-Borda, com suas proposições similares respectivamente de pesquisa-ação e investigaçãoação participante voltadas a fortalecer as transformações sociais a partir dos oprimidos. No Brasil, um dos principais autores da educação popular que busca avançar em metodologias participativas, principalmente a partir de Paulo Freire, é Carlos Henrique Brandão ${ }^{13}$.

Santos $^{1}$ questiona as metodologias qualitativas basicamente por duas razões: por se preocuparem em extrair conhecimentos apartados das lutas sociais, e por não reconhecerem os saberes dos sujeitos investigados, o que, de alguma forma, reforça uma visão colonial uma vez que nega a própria condição ontológica dos sujeitos excluídos enquanto portadores e produtores de saberes. É justamente dessa ideia de uma exploração sem limites que surge a analogia com o extrativismo enquanto regime de exploração econômica desenvolvido pelo capitalismo no 'Sul Global e intensificado nas últimas décadas na América Latina, mesmo nos governos liderados por partidos de esquerda. Para Santos, as ciências sociais desenvolvem métodos de investigação que estão mais preocupados em extrair informações de pessoas e comunidades transformadas em objetos, cujos conhecimentos possuem uma autoria restrita aos próprios pesquisadores especialistas, sistematicamente apartados das lutas sociais.

Os métodos qualitativos convencionais, em nome de uma pretensa objetividade ou neutralidade científica, estão mais preocupados em pesquisar entidades e processos exteriores aos próprios pesquisadores, portadores que são do conhecimento científico privilegiado. Como observam Santos ${ }^{1}$ e Nunes $^{14}$, tais métodos presumem a possibilidade e necessidade de uma ciência "neutra", de forma distinta das epistemologias do Sul que, sem confundir objetividade com neutralidade, assumem ética e politicamente o lado dos excluídos.

O problema para uma teoria crítica que se propõe transformadora passa a ser, sob a ótica das epistemologias do Sul, como pesquisar junto com os excluídos radicalmente em sua condição ontológica e enquanto detentores de saberes e sujeitos de direitos normalmente desprezados e invisibilizados. Como reconhecer tais sujeitos e criar condições para que possam potenciar a sua agência se os métodos de investigação adotados excluem sua condição de sujeitos, ignoram seus saberes e lutas fundamentais?

As epistemologias do Sul anunciam os saberes como situados, sendo validados localmente a partir de uma opção política que considera a forma como esses afetam os oprimidos. Traz, assim, um desafio ético àqueles que produzem conhecimento, pois os responsabiliza em relação aos efeitos de seus trabalhos no mundo. Portanto, o desafio estratégico reside em como construir conhecimentos junto com os excluídos concretizados em diversas pessoas, comunidades e movimentos sociais do 'Sul Global ', articulados com as lutas sociais por dignidade em curso e que considerem e fortaleçam os sujeitos enquanto portadores de direitos, saberes e capacidade de agenciamento. Este é, portanto, o sentido fundamental das metodologias colaborativas não extrativistas. Elas transcendem as propostas de pesquisas e metodologias participativas por considerarem a participação mais que uma devolução, partilha, troca ou empowerment junto aos sujeitos sistematicamente excluídos ou tutelados. Trata-se de pensar a pesquisa como uma 'co-criação' para a produção de conhecimentos 'co-labor-ativos', assim como a intervenção no mundo uma 'co-responsabilidade' decorrente do trabalho conjunto, um 'colaborar' de natureza simultaneamente ética, política e epistemológica.

Como as metodologias colaborativas implicam pesquisar 'com', o percurso da pesquisa e a trajetória de campo definidos previamente por certos pressupostos teóricos, hipóteses e métodos, ainda que críticos e 
participativos, sempre correm o risco de caminharem na direção oposta. Ao se fecharem para uma construção conjunta que permita reelaborar objetivos e métodos ao longo do próprio processo de investigação em bases éticas justificáveis, em tese um objetivo relevante de qualquer pesquisa, os pesquisadores não contribuem para o surgimento de novas questões e respostas que poderiam ser produzidas a partir dos desdobramentos decorrentes das relações com os saberes e contextos de luta dos sujeitos e movimentos sociais com os quais a pesquisa interage. Isso ocorre justamente quando sujeitos são transformados em objetos portadores de informações a serem analisadas por especialistas das ciências sociais ou de quaisquer outras áreas científicas, ainda que com as melhores intenções de produzirem o 'melhor` conhecimento ${ }^{13}$, ou como 'informantes ', como têm sido designados nas concepções dominantes de pesquisa qualitativa. Portanto, pensar metodologias colaborativas não extrativistas implica, mais que expressar diferentes perspectivas ou pontos de vista das populações ou comunidades, reconhecê-las como portadoras de saberes legítimos e com elas interagir. Este é o objetivo da ecologia de saberes ${ }^{10-12}$, que dessa forma busca fortalecer os sujeitos oprimidos envolvidos em lutas emancipatórias por reconhecimento e dignidade.

\section{Metodologias colaborativas e comunicação: produção de intersubjetividades para o inter-agir em diálogo com os excluídos e as lutas sociais}

Um desafio central das metodologias colaborativas é a criação de subjetividades e espaços de interações que transformem objetos em sujeitos, ou seja, conhecer não os outros, e não apenas para os outros, mas sim junto com os outros. Trata-se de tarefa extremamente complexa e difícil, e exige um exercício de tradução intercultural que crie os espaços de diálogo e inteligibilidade quando os grupos sociais que interagem possuem culturas, linguagens e histórias distintas9.

A comunicação, o tornar comum enquanto elemento constituinte central do viver em relação, éimportante fonte de inspiração para a construção de metodologias colaborativas de natureza relacional e processual. Tais metodologias caracterizam-se por produzir novos conhecimentos na medida em que articulam saberes a partir de processos inovadores de relacionamento e comunicação. Busca-se, dessa forma, superar os limites de métodos qualitativos convencionais, ainda que críticos, quando demasiadamente logocêntricos e preocupados com resultados embasados em referenciais, pressupostos e expectativas que se fecham ao novo, ao estranho e ao contingente. Métodos de registro e análise são tanto melhores quando favorecem a busca de diálogos com os grupos excluídos e as lutas sociais, como pela produção de relatos significativos enquanto atos de co-criação, co-laboração e inter-ação. Trata-se de abrir possibilidades que não coloquem o pesquisador numa perspectiva hierárquica de controle de qualidade e critérios de superioridade que os afastem dos sujeitos sociais excluídos, seus saberes e lutas. Tal postura colaborativa não extrativista, contudo, não significa rejeitar técnicas e métodos produzidos pelas ciências sociais que podem ser úteis para a pesquisa qualitativa.

Para enfrentar tais desafios, certamente complexos e incertos, e justamente por isso, precisamos nos apoiar em performances sensíveis e criativas que propiciem relações entre os sujeitos enquanto portadores e coprodutores de conhecimentos, um trilhar paradoxalmente mais preciso na medida em que caminha sem receitas prontas. A fluidez necessária a uma comunicação mais horizontal entre sujeitos implica espontaneidade, que não precisa se confundir com espontaneísmo anárquico. É por isso que os referenciais teóricos e metodológicos precisam se renovar e ampliar o repertório de sentidos e linguagens comunicativas para além do discurso logocêntrico que tende a ser excludente. Essa ideia tem forte conexão com o que Santos denomina artesania das práticas ${ }^{15}$, ou seja, a pesquisa e a metodologia compreendidas como um trabalho artesanal com as suas próprias regras, critérios de validação e de objetividade. A ideia aqui é que cada pesquisa pode ser compreendida como uma obra necessariamente singular, ainda que com 
semelhanças a outras produzidas anteriormente, porém originalmente (re)elaborada diante dos percursos, percalços e compromissos que surgem ao longo do processo investigativo.

O pesquisador que pretende trabalhar com metodologia colaborativa geralmente possui habilidades não restritas ao conhecimento dos métodos qualitativos e uma disposição para o engajamento solidário nas lutas sociais nos quais a pesquisa está inserida: sua habilidade central é a sensibilidade para escutar, dialogar e rever conjuntamente diversos elementos constituintes da pesquisa, como perguntas e estratégias de divulgação dos resultados. Daí decorre, em nossa avaliação, a inextricável relação entre as metodologias colaborativas não extrativas e a comunicação. Para ser colaborativa, uma pesquisa envolve necessariamente a construção e o exercício de intersubjetividades que abarquem múltiplos sentidos de ser, estar e perceber o(s) mundo(s) para a emergência de novos conhecimentos, assumidos sempre como um ato criativo mais solidário, não solitário nem de autoria individual, outra importante barreira e desafio para a realização de metodologias colaborativas.

Segundo Santos ${ }^{1}$, o entendimento da prática da pesquisa como uma artesania das práticas provém dos trabalhos seminais do sociólogo estadunidense Charles Wright Mills ${ }^{16}$, em especial sua proposta de imaginação intelectual e a ideia da investigação como um ofício e do pesquisador como um artesão. As proposições de Mills são respostas frente às críticas às tendências que dominavam a sociologia do seu tempo - e que hoje persistem sob formas renovadas - do que ele designava de "grande teoria" e de "empirismo abstrato". Tal perspectiva também vai ao encontro da ideia de Walter Benjamin ${ }^{17}$ em seu ensaio "O contador de histórias - Considerações sobre a obra de Nikolay Leskov", no qual denomina a arte da narrativa como a dimensão artesanal da comunicação. Para Benjamin, a fonte da narrativa está na necessidade humana de compartilhar experiências não só individuais como coletivas, que o contador de histórias vai incorporando a partir dos relatos que escuta na teia de relações em que está inserido. Com seu dom e sua sabedoria promove uma escuta que permitirá a seus ouvintes incorporarem tais narrativas às suas experiências e, dessa forma, continuarão a compartilhá-las com outras pessoas de suas comunidades, pois "a experiência que passa de pessoa em pessoa é a fonte a que recorrem os narradores"17. Segundo Benjamin, a arte de narrar estaria definhando, já que o conhecimento tecido na experiência, a sabedoria, não é reconhecida nem validada "com a consolidação da burguesia da qual a imprensa, no alto capitalismo, é um dos instrumentos mais importantes [...]”. Trata-se de uma reflexão crítica extremamente interessante para entendermos a comunicação e a informação na modernidade capitalista. A arte de narrar expressa uma atividade comunicativa que reinventa e inspira a vida ao tornar comum as experiências compartilhadas, enquanto a informação, no contexto da modernidade capitalista de acordo com Benjamin ${ }^{17}$, reflete uma pretensa verdade factual a partir de uma suposta objetividade e neutralidade, o 'fato `descoberto e revelado pelo jornalismo especializado da mídia. Em nossa perspectiva, essa objetividade se assemelha, em sua pretensão de verdade, ao conhecimento especializado obtido pelos cientistas, sendo tal compreensão mais uma das contribuições das epistemologias, ao aproximar as dimensões comunicacionais e epistemológicas das questões éticas e políticas relacionadas às lutas sociais. O fim da narrativa conectada às experiências individuais e coletivas representa, mais que a superficialidade do processo comunicacional, o fim da inspiração e da reflexão de outras possibilidades de pensar, viver e transformar, e é justamente isso que justifica nossa proposta de aproximação com a arte como uma das bases das metodologias não extrativistas, cuja natureza de co-criação é central.

Por isso, para nós o resgate da epistemologia implica o resgate das narrativas, da sabedoria e da arte como elementos constituintes do processo investigativo e da produção de saberes, sendo uma tarefa estratégica das metodologias colaborativas. Trata-se de outro caminho possível, que permite refletir sobre outras formas de pensar a pesquisa. Uma forma que se aproxima da abordagem 'teórico-poética' de incorporar e interpretar as experiências, tal como propõe Machado $^{9}$. Consideramos importante para a pesquisa qualitativa nos apropriarmos dessa proposta de aprendizagem na arte narrativa, de olhar para o tema que estamos investigando e interagir com ele simultaneamente de forma teórica e poética, permitindo "um espaço 
para o exercício de recursos internos - perceptivos e intuitivos"9. A junção entre análise intelectual teórica e percepção afetiva poética permitiria criar melhores condições de comunicação, outras formas de pensar e agir justamente porque a presença da narrativa traz vivas as questões do presente para construir possibilidades do que poderá vir a ser o futuro. A partir daí podemos assumir como, mais que confiança, a presença e a espontaneidade são dinâmicas importantes para a construção de alternativas, ou seja, para a própria sociologia das emergências, embora a busca consciente de tais dinâmicas não necessariamente garanta a emergência das alternativas almejadas.

Nenhuma poesia pode ser recitada da mesma maneira, seja naturalmente por pessoas diferentes, mas também em contextos diferentes, inclusive pelas mesmas pessoas. O improviso passa a ser estratégico a fim de alcançar a espontaneidade necessária e tornar a presença ativa marcante. Diferente do método rigidamente pré-programado, da repetição, do planejamento, ou de linguagens mais (pre)ocupadas com a participação ativa e autoral do espectador, o improviso apresenta outras formas de análise que tenham na interação mais livre e menos hierárquica entre os vários sujeitos o fio condutor do método. De certa forma, é justamente isso o mais interessante e profundo que buscamos realizar e pesquisar na investigação de temas como a experiência do documentário nas lutas sociais por saúde.

A proposta de artesania de práticas por Boaventura Santos busca atualizar o papel da imaginação e do trabalho artesanal enquanto diluidores de fronteiras rigidamente impostas pela modernidade eurocêntrica, que tendem a polarizar e distanciar ciência e arte, ou objetividade e subjetividade. Assumir tal posição não significa, contudo, que caiamos facilmente em relativismos ou incomensurabilidades que podem nos afastar das questões que, afinal de contas, ética e pragmaticamente, buscamos de alguma forma responder, ainda que com incertezas e incompletudes ${ }^{1}$. Frequentemente as questões com as quais trabalhamos implicam urgências decorrentes das lutas sociais e por sobrevivência frente às inúmeras formas de violências impostas aos excluídos. É por isso que Santos ${ }^{18}$ se contrapõe aos pensadores pós-modernos que assumem um relativismo cultural e renunciam a projetos coletivos utópicos de emancipação social.

Temos aqui um duplo desafio a enfrentar e que certamente interfere na questão metodológica. Por um lado, precisamos atuar com urgência para enfrentar brutalidades sem com isso nos desumanizarmos ou perdermos a vontade de continuar lutando solidariamente para transformar o mundo. Por outro, precisamos construir as condições de comunicação e diálogo - o tornar comum - para o conhecer e o agir em conjunto com os sujeitos da pesquisa. É por isso que Santos ${ }^{1}$ menciona a importância da dimensão terapêutica do fazer pesquisa quando trabalhamos com os excluídos. Essa dimensão é pouco reconhecida e trabalhada pela academia hegemonizada por uma visão de ciência 'objetiva' e desumanizada, apartada das lutas por dignidade. Isso se reflete em discussões metodológicas que raramente consideram a redução do sofrimento, especialmente o injusto e o desnecessário, a autoestima e a celebração da vida como componentes do processo de construção de conhecimentos.

Ao percebermos a relevância de componentes éticos e relacionais que exigem formas sensíveis de comunicação, torna-se inevitável ampliarmos nosso leque metodológico e abrirmo-nos para a incorporação de diferentes estratégias e expressões comumente desconsideradas no âmbito acadêmico. Falamos aqui da incorporação de inúmeros saberes e práticas que podem humanizar a pesquisa e os métodos utilizados a partir de uma ampliação dos sentidos corporais e afetivos que, ao vibrarem em ressonância com os diferentes sujeitos da pesquisa, permitem uma orquestração polifônica não apenas de vozes, mas um diálogo diferenciado, autêntico, que melhor se aproxima da dimensão ética pretendida por uma pesquisa colaborativa. Exemplos de saberes e práticas nessa direção são, entre outros, a música, o teatro, a pintura e, de especial interesse no trabalho de pesquisa que embasou as reflexões deste artigo, o audiovisual, a literatura oral e a contação de histórias a ela associada. Contudo, sobre essa diversidade de possibilidades de humanização para a construção de metodologias colaborativas somente nos debruçaremos após 
discutirmos sua relevância a partir de experiências de trabalhos de lutas sociais em redes junto com os movimentos sociais.

\section{Lutas por visibilidade, dispositivos comunicacionais e construção de saberes em redes com os movimentos sociais}

As epistemologias do Sul permitem lançar um novo olhar sobre a comunicação, seja ela em saúde ou qualquer outra área, pois evoca tarefas prioritárias como a emancipação social, o enfrentamento das desigualdades sem aniquilar diferenças identitárias, a relação dialógica com os movimentos sociais, o diálogo com as populações excluídas radicalmente e o reconhecimento de suas lutas, saberes e direitos. Enfim, a promoção de processos mais democráticos, inclusivos e dialógicos para a produção e circulação de sentidos, ideias e saberes na sociedade que fortaleçam a transição paradigmática e civilizatória.

Nas sociedades modernas e com fortes desigualdades sociais, a mídia hegemônica tende a ser mais um instrumento de opressão a serviço das classes dominantes ${ }^{19}$. Então, como fazer uma comunicação de modo emancipatório a partir das lutas populares que defendam e legitimem as suas aspirações? Tal questão é atualmente bastante relevante, já que o neoliberalismo busca destruir as alternativas ao atual modelo de concentração de riqueza e de destruição ambiental, usando justamente para isso de argumentos como a democracia e o direito à informação e aos meios de comunicação social. Em contraposição a essa visão, o discurso pós-colonial ressalta a dimensão política e epistemológica da dominação e das resistências, contribuindo para compreender como o discurso sustentado pelo modelo de ciência na modernidade é também um discurso colonial. Mídia e ciência caminham paralelamente, já que ambos se assentam na concentração de um poder que exclui outras formas de ser e saber, seja pela legitimação de um critério único de verdade pela ciência moderna, seja pelos mecanismos de difusão das informações e ideias produzidas e divulgadas pela mídia hegemônica.

Como apontam Araújo e Santos ${ }^{20}$, podemos perceber a linha abissal nos canais ou veículos de comunicação a partir da divisão estabelecida pela modernidade: a mídia atualmente é considerada exclusivamente aquela associada às tecnologias modernas, como a televisão, as rádios, a internet ou os jornais de grande circulação. Estes são considerados racionais, eficientes, 'modernos `. Por sua vez, grande parte das formas e canais de comunicação preexistentes à modernidade e que continuam sendo utilizados em várias partes do 'Sul Global', como os baseados na oralidade, na performance de rua, no teatro, na poesia popular como a literatura de cordel, todos esses dispositivos são 'não-tecnológicos ', e classificados como parte do "exótico, supersticioso, folclórico, arcaico e irrelevante". O pensamento abissal na comunicação termina "excluindo e/ou invisibilizando outras gramáticas de comunicação, outras vozes, narrativas e saberes"20.

Reconhecer o epistemicídio que ocorre a partir do monopólio da produção do conhecimento científico, configurada como único modelo, permite-nos enxergar o impedimento da emergência de outras formas de saber que não se encaixem nos critérios científicos de legitimidade. Da mesma maneira, reconhecer e enfrentar o monopólio da produção e circulação de informações, ideias e alternativas de sociedade configura-se como um desafio central para as lutas emancipatórias de nosso tempo, no qual a dominação simbólica se torna um elemento importante das relações sociais ${ }^{20}$. Nesses casos, a articulação entre estratégias políticas e discursivas pode privilegiar certos lugares de fala e invisibilizar outros, articulando-se dessa forma com um poder opressor. A comunicação aqui possui um papel estratégico para as lutas sociais e o que Santos ${ }^{10}$ denomina sociologia das ausências, a qual realiza a crítica e busca reverter a produção de realidades inexistentes pelo pensamento hegemônico. Grupos desprivilegiados e subalternizados no campo social também exercitam as sociologias das ausências e das emergências na medida em que produzem e circulam estrategicamente outros discursos com informações, saberes e interpretações que constituem artes e artesanias de resistência. Para Araújo e Santos ${ }^{20}$, é necessário promover uma sociologia das ausências 
que faça "emergir outras linguagens, outras narrativas, outras propostas, conhecimentos, testemunhos e experiências não apenas enquanto exercício cultural, mas como recusa de uma narrativa linear e monocultural e expansão da imaginação política para lá do ocidente".

Portanto, torna-se estratégico problematizar as implicações dos discursos reduzidos e das interpretações manipuladoras da realidade realizadas pelas abordagens dominantes, principalmente em relação aos processos de produção, circulação e apropriação de discursos e saberes. Para isso "novos atores, novas experiências têm vindo a ser reveladas e discutidas, alargando a base dos debates produzidos pelas críticas da modernidade à herança colonial”21. Exemplos dessas experiências são alternativas de comunicação articuladas às lutas sociais que vêm relacionando novas construções discursivas com o potencial de transformar e enfrentar os obstáculos ao uso de qualquer canal de comunicação, buscando uma melhor compreensão da natureza e das características de suas mediações culturais, sociais, institucionais e tecnológicas.

Essa perspectiva da comunicação indissociável das lutas sociais busca também desvelar os elos silenciados pelos processos de dominação dos interesses e das racionalidades hegemônicos. A noção de elo silenciado que propomos busca estabelecer uma conexão entre a comunicação e as epistemologias do Sul, pois revela e aprofunda a compreensão das formas sociais de produção da não existência de modos de ser, de saberes, experiências e alternativas que marcam o mundo contemporâneo em sua dimensão comunicacional. A nosso ver, a noção de elo silenciado se relaciona com a linha abissal na medida em que a não existência ontológica e epistemológica é ativamente produzida por processos simultaneamente invisíveis e invisibilizadores de discriminação como o racismo, a xenofobia e outras formas, os quais silenciam o que é considerado 'absurdo' ou 'primitivo'. A sociologia das ausências, em sua interface com a comunicação, busca compreender tanto os processos sociais de silenciamento nos quais certas formas de ser, existir e conhecer são desprezadas e ocultas, como o seu reverso, ou seja, as expressões de sentidos e saberes dos sujeitos excluídos.

Os elos silenciados podem dar mais clareza aos processos de invisibilização e visibilização dos sujeitos excluídos e seus saberes. Eles dizem respeito à não existência socialmente produzida de populações do 'Sul Global ', bem como aos processos de desqualificação de tudo o que contradiz ou se coloca como alternativa ao que é considerado pela racionalidade monolítica moderna como 'progresso', 'científico', 'produtivo', 'universal' e 'global'. Uma comunicação emancipatória busca explicitar tais elos silenciados em diferentes espaços e com o apoio de diferentes mídias e linguagens, tornando visíveis e fornecendo credibilidade desde às questões como as violências realizadas contra populações radicalmente excluídas até às alternativas presentes e produzidas pelas lutas sociais, de modo a reforçar o poder de agência das populações e dos movimentos sociais envolvidos. Nesse sentido, o elo, como metáfora, não pode ser considerado apenas enquanto perdido, sendo este decorrente dos genocídios e epistemicídios. Os elos silenciados permanecem enquanto realidades sociais, ontológicas e epistemológicas presentes na realidade do Sul Global, do 'lado de lá' da linha abissal, e por isso são invisibilizados, considerados não existentes. São possibilidades reais de transformação justamente não só porque existiram ou são utopias, mas porque existem e disputam outros tipos de sociedade, convívio e economia. Exemplos concretos são a agricultura camponesa e agroecológica, as feiras diferenciadas que integram mercado, a solidariedade e o intercâmbio de experiências, assim como inúmeros conhecimentos e concepções de saúde provenientes das populações dos campos, florestas e águas.

No caso da pesquisa referida anteriormente envolvendo os movimentos sociais do campo, a emergência dos elos silenciados manifesta-se nas proposições e articulações de lutas sociais que conectam tanto denúncias (as lutas contra a agricultura industrial capitalista e os agrotóxicos) como alternativas (a agricultura camponesa e agroecológica). Ambas expressam e atualizam questões com múltiplos sentidos de economia, trabalho, ambiente e saúde que são constitutivas desses elos silenciados. Tais questões consubstanciam-se em diferentes temáticas e proposições que passam a fazer parte do vocabulário das lutas: alimentação saudável; trabalho digno, autônomo e sem exploração; o direito à terra e à reforma agrária; 
o reencontro entre sociedade, produção, trabalho e natureza na busca de um meio ambiente equilibrado; educação e saúde no campo que considere a singularidade dessas populações e seus conhecimentos; o papel e a função social da ciência explicitando suas incertezas e contradições éticas.

Na realidade, trata-se de um grande desafio tanto epistemológico quanto político construir processos que expressem para a sociedade o que está em jogo nesse debate. A questão dos agrotóxicos é particularmente exemplar para tornar mais explícito o papel da ciência, suas incertezas, contradições e problemas éticos. Há todo um investimento num modelo de ciência aplicada à agricultura para o controle das 'pragas' e o aumento da produtividade agrícola, cujos resultados fazem parte das inovações tecnológicas do agronegócio que integra o mercado de exportação de commodities para a economia global. Nessa perspectiva hegemônica, a agricultura familiar camponesa e a agroecologia, com suas práticas agrícolas 'primitivas' e propostas de um mundo 'utópico' de integração entre sociedade, economia, produção e natureza com solidariedade, não representariam alternativas plausíveis para um mundo 'moderno', 'produtivo', tecnológica e economicamente eficiente. Do lado hegemônico encontram-se não só as vozes do agronegócio e dos defensores dos agrotóxicos, mas de boa parte das instituições modernas, da ciência clássica e, certamente, da mídia hegemônica, que é financiada pelos setores econômicos mais poderosos e reproduz a racionalidade monolítica dominante. Do lado das populações oprimidas, cuja existência é negada e sistematicamente silenciada, encontram-se camponeses, movimentos sociais do campo e, ainda, organizações e cientistas ativistas que solidariamente se aliam aos que lutam para tornar plausível um mundo agroecológico e sem venenos. As lutas sociais de tais grupos não pretendem apenas desconstruir argumentos do outro lado, mas romper as barreiras que silenciam e condenam à não existência seus saberes e suas experiências. Tratase, portanto, de uma batalha simultaneamente epistemológica, comunicativa e política que busca romper com a comunicação imposta para o controle e a dominação, desvelando outras racionalidades e vozes que ampliem o presente, por conseguinte, possibilitem outros futuros. O processo de visibilização dessas vozes silenciadas é tarefa da sociologia das ausências, mas quando essas falam e experienciam alternativas sociais críveis que se apresentam, temos a sociologia das emergências. Esta consiste "numa amplificação simbólica de sinais, pistas e tendências latentes que, embora dispersas, embrionárias e fragmentadas, apontam para novas constelações de sentido referentes tanto à compreensão como à transformação do mundo"11.

Ao falarmos da comunicação a partir das lutas e movimentos sociais, levantam-se temáticas como a questão do direito à comunicação; da comunicação em rede; do acesso à informação por parte de grupos e classes excluídos e discriminados; da criação de sistemas alternativos de comunicação como forma de rejeição aos regimes hegemônicos. A comunicação em rede torna-se uma questão estratégica. Por exemplo, onde esta rede é operada pelos que produzem e fazem circular seus sentidos, ao mesmo tempo que se apropriam de outros discursos circulantes, permite inovações nos sentidos sociais ${ }^{22}$. Comunicação, informação e educação popular articulam-se em torno dessa concepção de redes, construindo um pensar e agir com alianças entre movimentos sociais, organizações comunitárias e étnicas, universidades, sindicatos, igrejas, entre outros. Tais redes produzem e compartilham conhecimentos de outra natureza que os científicos e com esses saberes realizam disputas simbólicas para serem reconhecidos e transformarem a sociedade ${ }^{22}$.

Os movimentos aos quais nos referimos ressurgem nas últimas décadas na América Latina com pluriagendas e suas novas modalidades de lideranças ${ }^{23}$, trazendo novas bandeiras e sujeitos políticos. Inúmeras questões são levantadas, entre elas as lutas pelo reconhecimento dos territórios indígenas e saberes ancestrais, pela reforma agrária e pela agroecologia por camponeses e agricultores familiares, além da busca de afirmação de identidades, territórios, culturas, cosmovisões, com o resgate e ressignificação dos sentidos de vida, trabalho, saúde e natureza. O questionamento ao modelo de sociedade alinha-se com as teorias pós-coloniais e das epistemologias do Sul, pois aponta-se como horizonte utópico sociedades pós-capitalistas, pós-coloniais e pós-patriarcais, enfim, pós-abissais. Ideias de Boaventura de Sousa Santos como uma globalização contra hegemônica através da transescalaridade das lutas sociais ${ }^{24}$, concretizam-se por meio da ação global de fortes 
movimentos de raízes territoriais, como o movimento indígena, quilombola, trabalhadores rurais sem terra, pescadores artesanais e outros povos e comunidades tradicionais. Tais ações, amplamente apoiadas em dispositivos comunicacionais como a internet e a produção audiovisual, desafiam os movimentos globais a ressignificar seus conceitos, horizontes de luta e estratégias de intervenção. A forma como tais dispositivos são realizados tornam-se, a nosso ver, campos empíricos relevantes para compreender a construção de metodologias colaborativas que conectam dimensões comunicacionais e epistemológicas.

O audiovisual, em especial o documentário, vem sendo crescentemente utilizado por movimentos sociais em articulações e alianças com cineastas e setores da academia para refletir e fazer circular ideias e práticas normalmente silenciadas sobre as denúncias e as alternativas para as transformações sociais, econômicas e políticas contemporâneas. O documentário tem caminhado junto com a sociologia, antropologia, a história, a literatura eos estudos sobre a cultura enquanto espaço relevantena atualidade para a produção depensamentos e reflexões contra-hegemônicos. A produção na última década de documentários em torno das denúncias ao modelo do agronegócio e das alternativas colocadas pela reforma agrária e a agroecologia são exemplos de como o audiovisual articula dimensões comunicacionais e epistemológicas ${ }^{5}$, revelando, de múltiplas formas, contradições e possibilidades de transformação social a partir de lutas em curso por outros mundos possíveis. Diversos documentários abordam múltiplos objetivos do movimento social por meio de denúncias e discursos políticos criados social e artisticamente que enfatizam estruturas narrativas convincentes e dialogam com os sujeitos das lutas sociais e com a própria ciência. Neste caso, dados de pesquisas científicas organizadas por pesquisadores que dialogam de outra forma com os saberes e lutas sociais dos movimentos e populações do campo permitem estabelecer limites, confrontar e desconstruir discursos produzidos e/ ou legitimados por cientistas frequentemente financiados pelo agronegócio e pelas indústrias químicas. Na perspectiva das epistemologias do Sul, podemos compreender e analisar documentários dessa natureza enquanto estratégia comunicacional e epistemológica que promove o fortalecimento e visibilidade das lutas sociais. Mais do que apenas uma obra artística e política de comunicação, esses documentários podem ser pensados enquanto exercício de uma ecologia de saberes, de práticas colaborativas envolvendo relações entre cineastas, pesquisadores e movimentos sociais considerados como sujeitos portadores de saberes que lutam por reconhecimento. Documentários dessa natureza enfrentam inúmeros dilemas teóricos, metodológicos e éticos que são os mesmos, em princípio, das pesquisas que se propõem colaborativas e dialógicas para atuar junto com os sujeitos em luta por reconhecimento e dignidade.

\section{Co-criação, artesania das práticas, entrevistas narrativas e relatos significativos na metodologia colaborativa}

Algumas questões de método surgem inevitavelmente num projeto como o que serviu de base a esta discussão: será possível, como e até onde, mobilizar as metodologias, as técnicas e os procedimentos de pesquisa e criação próprios das formas canônicas de pesquisa como outras formas não canônicas de criação estética e artística? O que significa colaborar e criar em colaboração, quando se está perante um encontro de experiências, linguagens e formas de expressão diferentes cuja inteligibilidade mútua está longe de ser garantida?

A colaboração, enquanto característica das questões metodológicas aqui propostas, não pode ser encerrada na formalização de um roteiro e na definição de técnicas que atribui lugares e tarefas específicas a diferentes participantes, em momentos definidos num cronograma. Colaborar significa, aqui, trabalhar em conjunto sem que o processo e o resultado do trabalho estejam garantidos previamente a essa colaboração. Ela não depende de um inventário prévio de participantes, ou sequer de roteiros que tracem uma direção pré-definida, com etapas correspondentes a tarefas cuja necessidade, relevância ou conteúdo são conhecidos de antemão. Os exemplos que podem servir de inspiração para a colaboração assim entendida podem ser 
encontrados em diferentes práticas estéticas-expressivas, como a música, a dança, o teatro, a contação de histórias, ou ainda em outras práticas com características artesanais. Todas estas práticas envolvem maneiras de combinar e entretecer matérias de vários tipos, competências incorporadas, procedimentos que combinam diretrizes partilhadas com o improviso próprio dos processos de transformar e criar. Santos ${ }^{25}$ propõe o termo "artesanias" para descrever esse trabalho completado em situação, mas sempre a recomeçar, que usa os recursos conhecidos para criar algo sempre novo. Nesse processo, formas de expressão distintas, linguagens diversas e uma heterogeneidade de práticas aprendem a criar em colaboração, em encontros que estabelecem, de maneira situada, os espaços em que as ecologias de saberes e de práticas podem emergir. Destas experiências nascem novas configurações de saberes, novas histórias, novas maneiras de produzir a vida em comum, o conhecimento, os modos de afetar e de ser afetado/a.

As metodologias convencionais das ciências sociais e as técnicas que as embasam adquirem, nesse processo, o estatuto de ferramentas que podem contribuir para a construção de novas artesanias, com a condição de serem incorporadas em novas configurações de saberes e de práticas situadas, em processo de interlocução e diálogo com outras práticas e outros saberes, orientados para resposta a problemas ou desafios situados. A definição e compromissos em torno dos quais problemas e desafios precisam ser priorizados implicam um processo coletivo e dialógico, novamente, um tornar comum que é um objetivo central do processo comunicacional e que fornece sentido à condição humana. Torna-se claro que a construção deste comum, seja um bem comum, um saber novo comum, ou respostas comuns a problemas comuns e urgentes porque enfrentam a negação da humanidade de certas populações, são tarefas do pensamento pós-abissal que exigem novos horizontes comunicacionais como base para novos saberes e práticas.

É nesse contexto que podemos falar de uma diluição de fronteiras ou maior porosidade entre os campos da epistemologia, comunicação e arte como constitutiva de um pensamento pós-abissal. A desconstrução e a reconstrução de paradigmas a partir de encontros reais e horizontais com outros saberes abarca, como já dito, uma artesania das práticas. O fluir comunicacional envolve formas de espontaneidade e improviso necessários, ao construir o comum justamente a partir do diferente. Por isso, a investigação colaborativa precisa ser construída de outra forma que não somente a logocêntrica formal e erudita.

As epistemologias do Sul não procuram substituir um paradigma por outro ou escolher entre paradigmas alternativos. O que procuram fazer é precisamente propor um olhar diferente, que possa considerar cada proposta ou corrente teórica naquilo que propõe e também naquilo que omite ou suprime, daí a noção de sociologia das ausências. Nada impede que diferentes conceitos e proposições teóricas sejam usados, ou que diferentes métodos já existentes possam ser incorporados à pesquisa. Nesse sentido, são basicamente dois os princípios metodológicos mais relevantes: a participação social ativa dos pesquisadores nas lutas travadas pelos grupos e movimentos sociais com quem trabalham, e evitar excluir possibilidades ancoradas num único enfoque ou paradigma. O que importa é que essa escolha seja feita considerando o tema, o problema, o contexto em que se trabalha, os saberes e práticas que a situação nos apresenta e os modos de definir a melhor configuração de conceitos e de métodos que permita lidar com a situação, tendo em conta as limitações identificadas no exercício de sociologia das ausências. As epistemologias do Sul não pretendem ser uma alternativa a mais, mas um pensamento alternativo de alternativas ${ }^{10}$. Não se descarta nenhuma contribuição teórica ou metodológica existente, mas elas são sempre escolhidas e usadas em função do problema, da situação e do contexto por meio da criação das artesanias das práticas adequadas, que permitam diálogos ou a coexistência de conceitos e métodos diferentes, incluindo os que são próprios de todas e todos os/as participantes. Para isso, é necessário passar por um processo de análise das exclusões, supressões e ausências que a formalização implica.

Portanto, não há qualquer negação a priori de qualquer método ou técnica que possa ser útil ao trabalho de investigação. Pelo contrário, o que se procura precisamente evitar é a negação ou o descartar de outras possibilidades diferentes das que caracterizam as nossas teorias ou metodologias favoritas, a criação de 
uma monocultura de pesquisa que fica fechada num único enfoque ou paradigma. Tal posicionamento condicionaria as possibilidades de pesquisa aos temas que podem ser configurados a partir desse enfoque. $\mathrm{Ou}$ seja, as epistemologias do Sul não são um paradigma, mas a possibilidade de identificação, reconhecimento e facilitação do diálogo entre elementos considerados como próprios de paradigmas distintos e dos seus pressupostos teórico-metodológicos e ferramentas, em função dos problemas em situação e em contexto. É tal perspectiva que buscamos apresentar neste artigo.

As práticas e saberes da produção audiovisual, da entrevista narrativa ou da história de vida podem, assim, ser convertidas em recursos para a criação colaborativa de novas formas de expressão e partilha de experiências, em particular das que são forjadas em lutas pela justiça social, histórica e cognitiva. Existem algumas referências no âmbito das ciências sociais que têm aprofundado o papel da performance e das artes e que servem de inspiração para a construção de metodologias colaborativas, que discutem o tema das diferenças e os processos de transformação a partir de distintos contextos e interações culturais. Elas nos falam da importância de se ouvir os detalhes, decorrendo daí a importância da interescuta, uma outra forma de se comunicar mais atenta e profunda. Embora a música una os exemplos aqui citados, dada a inspiração provenientes de ritmos, construção de melodias e dissonâncias que respeitem diferenças, improvisos e formas mais espontâneas de seguir juntos, também poderíamos acrescentar o olhar ou outros sentidos do corpo e do espírito trabalhados por outras artes e linguagens.

Do ponto de vista da metodologia colaborativa, outro aspecto importante diz respeito aos diálogos e às entrevistas que ocorrem ao longo do processo investigativo. Na perspectiva proposta, uma comunicação profunda entre os vários sujeitos da pesquisa busca superar o fosso existente entre o pesquisador que extrai informações dos entrevistados para serem posteriormente analisadas. Na co-criação, o foco passa a ser a construção de narrativas que tragam à tona elementos ou relatos significativos em termos de prioridades estratégicas de luta, saberes situados e ações voltadas à transformação. Mais que discursos obtidos a partir de entrevistas a serem objetivamente analisados, o que está em jogo são formas de comunicação vivas obtidas através de narrativas, histórias e relatos significativos.

As pesquisas baseadas em narrativas vêm ganhando importância, fato este relacionado à crescente consciência do papel que contar histórias desempenha na conformação de fenômenos sociais. Segundo o semiólogo e crítico literário Roland Barthes: “[...] A narrativa está presente em mito, lenda, fábula, conto, novela, epopeia, história, tragédia, drama, comédia, mímica, pintura, vitrais de janelas, cinema, histórias em quadrinhos, notícias, conversação. Além disso, sob esta quase infinita diversidade de formas, a narrativa está presente em cada idade, em cada lugar em cada sociedade; ela começa com a própria história da humanidade e nunca existiu, em nenhum lugar e em tempo nenhum, um povo sem narrativa [...] ela está simplesmente ali, como a própria vida.”26

A entrevista narrativa tem como objetivo central incentivar o entrevistado a contar a história de algo da sua vida e do contexto social ${ }^{27}$. A técnica recebe seu nome da palavra latina narrare, contar uma história. Assume-se que o contar histórias implica estados intencionais que aliviam, ou ao menos tornam familiares, acontecimentos e sentimentos presentes na vida cotidiana, profissional ou mesmo artística. Este método se coloca como alternativa às entrevistas diretas ou mesmo semiestruturadas, que tendem a criar barreiras à espontaneidade necessária para o fluir de relatos mais vivos e significativos em torno de certas temáticas ou situações.

A entrevista narrativa tem como fundador e principal expoente no campo das ciências sociais os trabalhos do sociólogo alemão Fritz Schütze entre as décadas de 1970 e 1990²7. A ideia básica deste autor é reconstruir e reconstituir acontecimentos sociais a partir das perspectivas dos entrevistados, tão espontânea e diretamente quanto possível, com a menor interferência por parte dos pesquisadores. Trata-se de uma proposta sistemática de criar narrativas com fins de pesquisa social, que se constitui enquanto alternativa de pesquisa qualitativa de forma não estruturada, considerada de profundidade e com características próprias. Para além de uma menor interferência do pesquisador, é necessária a construção de um ambiente de 
espontaneidade e liberdade para empregar esse tipo cotidiano de comunicação, o contar e escutar história. Isso vai ao encontro da proposta de uma ecologia de saberes quando $\operatorname{Santos}^{28}$ afirma: "a primeira coisa é que esses cientistas têm que saber escutar, e não apenas falar. Saber escutar profundamente é um dos princípios básicos da ecologia de saberes".

Em termos de método, a entrevista narrativa tem por base o contar histórias e possui exigências inerentes à narrativa enquanto um processo semiautônomo, ativado por uma situação predeterminada. A narrativa é iniciada, então, a partir de provocações específicas e, uma vez que o entrevistado tenha começado, o contar história irá sustentar o fluxo da narração, fundamentando-se em algumas regras subjacentes do processo narrativo.

Histórias narradas podem ser pensadas enquanto construção de intersubjetividades entre entrevistador e entrevistados a partir de processos mais plenos de engajamento que promovam o expressar de experiências, sentimentos, saberes e reflexões dos sujeitos entrevistados. Essa ativação é disparada quando ele próprio, o sujeito entrevistado, torna-se um contador de histórias e, dessa forma, surgem relatos significativos repletos de detalhes que formam o fermento e o tempero da comunicação. Para avançar nessa linha, partimos de uma experiência profissional anterior no estudo e prática das histórias da literatura oral nos processos educativos de sensibilização, a fim de dinamizar processos criativos e reflexivos ${ }^{29}$. Acreditamos que tal proposta caminha na direção das metodologias colaborativas, ao permitir a emergência de condições criativas e sensíveis de aproximação e construção de intersubjetividades entre os participantes da pesquisa.

A relação entre a contação de histórias da literatura oral por meio de realização de entrevistas narrativas e a produção de relatos significativos pode ser vista sob três aspectos. Primeiro, como um ponto de partida, pois o que se pretende com entrevistas narrativas é a mobilização das pessoas entrevistadas enquanto sujeitos que possam se expressar o mais livre e integralmente possível. Essa é a ideia de relatos significativos, que são aqueles em que os entrevistados possuem confiança e liberdade para produzirem reflexões densas que tenham relação com suas identidades, contextos, necessidades e saberes situados. É a partir daí que podemos buscar compreender o significado das lutas por existência e dignidade que está por detrás das denúncias, dos anúncios ou alternativas. Contar histórias no início ou ao longo de uma conversa pode se constituir em dispositivos que geram empatias, confiança e abertura do próprio entrevistado para o ato de narrar. Um relato significativo depende de um estado de espírito livre, um voar discursivo espontâneo que permita uma conexão alinhada com sentidos profundos de uma pessoa em dado contexto social. Ao mesmo tempo, o caráter fantasioso, mágico, anedótico e paradoxal de histórias da literatura oral abre portas e contribui para quebrar padrões rígidos, desconfiados, excessivamente lógicos, lineares e impessoais que podem ser induzidos pelo contexto em que as entrevistas são realizadas.

O segundo aspecto se refere à analogia que os relatos significativos possuem com a literatura oral. Mais relevante que a rígida separação entre fatos e valores, ou ficção e não ficção, é a densidade, a complexidade, as reflexões e os sentimentos invocados que se encontram por detrás das narrativas. Tal como o recitar de uma poesia, performance e discurso fundem-se para produzir e alcançar relatos significativos; da mesma forma, uma boa história da literatura oral pode funcionar como inspiração para o relato.

Considerando os aspectos mencionados, assumimos que contar histórias da literatura oral pode ser um bom ponto de partida para as entrevistas narrativas, pois pode contribuir para inspirar o relato das experiências pessoais dos entrevistados dado o poder da metáfora e do encantamento por elas produzidas. Ao mesmo tempo, pode operar como estratégia de aproximação e diálogo mais horizontal entre os participantes da pesquisa. Trata-se de uma abordagem metodológica de pesquisa na qual as metáforas e analogias das histórias são pensadas para negociar a distância e as formas de aproximação entre diferentes saberes e perspectivas nos processos de produção e atribuição de sentidos. A intenção nessa prática é proporcionar uma relação impregnada de afetos e sensações, buscando pensar a realidade por meio do encantamento ${ }^{28}$. $\mathrm{O}$ encantamento é entendido aqui no sentido de que as histórias podem promover uma distração da atividade puramente racional, passando assim a ser escutadas não só em seus conteúdos objetivos, mas também 
considerando o contato com experiências prévias, conectando com sentimentos em contextos mais livres de expectativas de comportamento presentes em ambientes formais de entrevistas de pesquisa.

Em outras palavras, histórias da tradição oral permitem o contato com a própria experiência dos envolvidos por meio das percepções que afloram no processo de contar e escutar histórias, sendo a metáfora das histórias o canal de acesso a essas experiências. Nesse sentido, redescobre-se a oralidade como linguagem e expressão de saberes que, de outra forma, não poderiam ser transmitidos e fazer parte de processos dialógicos. Como nos sugere Boaventura de Sousa Santos, uma história de origem permite a conexão e engajamento ativo com outras histórias, numa dinâmica que possibilita a construção de outros relatos e outros textos.

\section{Conclusão}

Entendemos que, ao discutirmos o audiovisual e o documentário em contextos de lutas sociais do Sul Global, abre-se um leque de perspectivas metodológicas para pensar e conduzir de forma colaborativa, criativa e compartilhada o fazer a pesquisa em sua dimensão comunicacional. Tal leque propicia construir pontes e avanços a partir das epistemologias do Sul no entendimento freiriano da comunicação enquanto processos dialógicos na permanente busca do tornar comum. Somos desafiados a pensar como podemos produzir outro tipo de conhecimento a partir de linguagens outras, não logocêntricas, que possibilitem os diversos sentidos corpóreos e afetivos enquanto possibilidades de comunicação e expressão de saberes. Não casualmente, diversos espaços dos movimentos sociais do campo e da agroecologia que protagonizam os documentários focados em nossa investigação combinam a expressão 'saberes e sabores', como em feiras e espaços de encontros entre movimentos sociais e grupos acadêmicos.

Assumimos, como complementar às epistemologias do Sul, uma abordagem teórico-poética9 que, ao incorporar diferentes linguagens, pode contribuir para o desenvolvimento de metodologias colaborativas por envolver tanto a dimensão corpórea concreta com o mundo da sobrevivência e superação das distintas formas de violência, como a dimensão criativa e existencial em torno da imaginação e construção de novos mundos possíveis a partir das experiências cotidianas envoltas na cultura. A dimensão utópica, tão fragilizada ao entrarmos no século XXI, pode ser resgatada a partir da integração e expressão não apenas de experiências, mas de sentidos, saberes e sonhos emancipatórios construídos nas frestas das opressões e distopias em curso.

Para as epistemologias do Sul, a comunicação implica a necessidade de se escutar profundamente, e, para isso, torna-se fundamental associar o silêncio e a noção da incompletude, assim como conceber espaços de interconhecimento; cabe salientar que um constante aprofundamento da consciência da incompletude e do diálogo podem promover a autorreflexão e permitir a articulação entre diferentes saberes e culturas. Assumimos que a transculturalidade ou o diálogo intercultural pode contribuir para criar modos supostamente mais ricos, democráticos de convívio, o que é possibilitado por diálogos por vezes repletos de estranhamentos e tensões, mas que permitem o reconhecimento das construções próprias e alheias enquanto bases de transformação social. Para pôr em prática uma metodologia colaborativa, é fundamental conceber espaços articulados, sensíveis e criativos de intersubjetividades e interconhecimentos.

O audiovisual, em particular o documentário enquanto dispositivo comunicacional, que é um objeto da pesquisa já mencionada, pode ser visto de duas maneiras em sua relação com as metodologias colaborativas enquanto estratégia de produção de conhecimentos. Primeiro, o documentário expressa, em sua produção e contexto, mais que uma estratégia comunicacional e uma polifonia de vozes no sentido dado por Bakhtin ${ }^{30}$, uma polifonia de sentidos, pensamentos e sentimentos a serem trabalhados, transformados e orquestrados para o tornar comum a partir de processos e relações dialógicas que articulem simultaneamente dimensões epistemológicas e comunicacionais. Ou seja, serve de palco para 
a emergência de uma ecologia de saberes simultaneamente à produção e circulação de novas formas de compreender e transformar a realidade. Segundo, e como consequência do primeiro, o documentário, seu processo de produção, desde o roteiro a captação de imagens e sons até a edição final e formas de divulgação, serve como metáfora inspiradora para se pensar a própria investigação a partir de metodologias colaborativas que invertam o papel e as possibilidades do investigador e da pesquisa na direção de um trabalho de co-criação co-labor-ativa. Arte, performance e história oral são possibilidades concretas de tornar vivas as comunicações, diálogos e entrevistas que formam a matéria-prima de metodologias colaborativas baseadas na co-criação e no respeito mútuo.

\section{Referências}

1. Santos BS. A sociologia pós-abissal: metodologias não extractivistas [Internet]. Coimbra: Universidade de Coimbra; 2017 [citado em 2018 out. 10]. Vídeo: 1 h 35 min 20s. Disponível em: https://goo.gl/pvB1ze

2. Freire P. Extensão ou comunicação? 3. ed. Rio de Janeiro: Paz e Terra; 1977.

3. Fals-Borda O. La ciencia y el pueblo: nuevas reflexiones. In: Salazar MC, organizadora. La investigaciónacción participativa. Inicios y desarrollos. Madrid: Popular; 1992. p. 65-84.

4. $\quad$ Araujo IS, Cardoso JM. Comunicação e saúde. Rio de Janeiro: Editora Fiocruz; 2007.

5. Fairclough N. Discurso e mudança social. Brasília: UnB; 2001.

6. Araujo IS. Mercado simbólico: um modelo de comunicação para políticas públicas. Interface (Botucatu). 2004;8(14):165-77.

7. Fasanello MT, Araujo IS, Porto FS. Produção audiovisual nas lutas dos movimentos sociais do campo no Brasil: dimensões comunicacional e epistemológica. Commons. R Comunic Ciudad Dig. 2016;5(2):118-47.

8. Fischlin $D$, Heble A. The other side of nowhere: jazz improvisation and communities in dialogue. Connecticut: Wesleyan University Press; 2004.

9. Machado RSB. Rasas razões. In: Barbosa, AM, organizadora. Inquietações e mudanças no ensino da arte. São Paulo: Cortez; 2008. p. 175-80.

10. Santos BS, Meneses MP. Epistemologias do Sul. São Paulo: Cortez Editora; 2014.

11. Santos BS. Para além do pensamento abissal: das linhas globais a uma ecologia de saberes. Novos Est Cebrap. 2007;79:71-94.

12. Santos BS, Araújo S, Baumgarten M. As Epistemologias do Sul num mundo fora do mapa. Sociologias [Internet]. 2016 [citado em 2018 out. 20];18(43):14-23. doi: https://dx.doi.org/10.1590/15174522$\underline{018004301}$

13. Brandão $C R$, organizador. Pesquisa participante. São Paulo: Brasiliense; 1980.

14. Nunes JA, Siqueira-Silva, Raquel. Dos "abismos do inconsciente" às razões da diferença: criação estética e descolonização da desrazão na Reforma Psiquiátrica Brasileira". Sociologias. 2016;18(43)208-37.

15. Santos BS. A filosofia à venda, a douta ignorância e a aposta de Pascal. In: Santos BS, Meneses MP. Epistemologias do Sul. São Paulo: Cortez Editora; 2014. p. 467-507.

16. Mills CW. The Sociological imagination. Harmondsworth: Penguin; 1959.

17. Benjamin, W. O contador de histórias: reflexões sobre a obra de Nikolai Leskov. In: Walter B. Linguagem tradução, literatura. Obras Escolhidas de Walter Benjamin. Barrento J, editor e tradutor. Porto: Assírio \& Alvim; 2015. p. 147-178.

18. Santos BS. Do pós-moderno ao pós-colonial. E para além de um e de outro. Travessias, R Lit Ci Soc Língua Port. 2007;6/7:36.

19. Santos BS. Epistemologias do Sul: desafios teóricos e metodológicos [Internet]. Coimbra: Universidade de Coimbra; 2016. [citado em 2018 out. 10]. Vídeo: 1h 22min 45s. Disponível em: https://www. youtube.com/watch? $v=q 75 \times$ WUBI8aY 
20. Araújo S, Santos SJ. Os media e a proposta das Epistemologias do Sul. JANUS. 2017;78-79.

21. Meneses MP. Epistemologias do Sul. R Crít Ci Sociais. 2008 mar.;80:5-10.

22. Marteleto R, Valla F. Informação e educação popular: o conhecimento social no campo da saúde. Perspect Ci Inf. 2003 jul./dez.;8(n. especial):8-21.

23. Gohn MG. Abordagens teóricas no estudo dos movimentos sociais na América Latina. Cad CRH. 2008;21(54):439-55.

24. Santos BS. A gramática do tempo. Para uma nova cultura política. São Paulo: Cortez; 2006.

25. Santos BS. Tradução intercultural e luta social na esteira de Gandhi [Internet]. Coimbra: Universidade de Coimbra; 2017 [citado em 2018 out. 10]. Vídeo: 1h 21min 10s. Disponível em: https://goo.gl/AwFrEM

26. Barthes R. Introdução à análise estrutural da narrativa. In: Barthes R, Greimas AJ, Bremond C, Eco U, Gritti J, Morin V et at. Análise estrutural da narrativa. 7. ed. Rio de Janeiro: Vozes; 2011.

27. Jovchelovitch S, Bauer MW. Entrevista narrativa. In: Bauer MW, Gaskell G, organizadores. Pesquisa qualitativa com texto, imagem e som: um manual prático. 12. ed. Petrópolis: Vozes; 2014. p. 90-113.

28. Carneiro FFF, Krefta NM, Folgado CAR. A praxis da ecologia de saberes: entrevista de Boaventura de Sousa Santos. Tempus. 2014;8(2):331-8.

29. Fasanello MT. Cinema, literatura oral e pedagogia da criação: reflexões a partir do projeto "A escola vai à cinemateca do MAM" [dissertação]. Rio de Janeiro: Universidade Federal do Rio de Janeiro; 2013.

30. Bakhtin M. Estética da criação verbal. São Paulo: Martins Fontes; 1997. 